\title{
An Example of the Variation of the Oceanographical Condition of Enshu-nada*
}

\author{
By \\ Shigeo MORIYASU**
}

$\S 1$. Since 1954 a cold water mass has been observed in Enshu-nada, which is comparable with the cold water mass appearing from 1936 to 1942 . Many oceanographers ${ }^{12)}$ studied the structure of the cold region, and the outline of it has been made clear. The representative oceanographical condition in the appearance of the cold region is as follows : the current axis of the Kuroshio was far away from coast to the south of Shionomisaki and then flowed round the cold region of temperature below $16^{\circ} \mathrm{C}$ at the depth of $100 \mathrm{~m}$. Such condition was found in 1954 and seems to have continued up to now. But, since the observations were not carried out frequently, it is difficult to see the variation of short period. In Oct. 1954, repeated observations as shown below were made in Enshu-nada, which indicated considerable variations in oceanographical conditions.

Observation A

Date Stations

Oct. $2 \sim 3 \quad N_{1} \sim N_{9}$ operated by Central Me-

Oct. $4 \sim 5 \quad H_{2} \sim H_{9}$ teorological Observatory

Observation B

Date Stations

Oct. 13 14 501 506 operated by Maritime Safety Agency

Oct. 15 17 $\quad D_{1} \sim D_{11}$

Oct. 19 22 $G_{1} \sim G_{7}$ operated by Kobe Marine Observatory

In this paper, I intend to show the variation in question using these data.

$\S 2$. First we shall show the hydrographical conditions in both observations respectively.

Observation A

The cold region was observed as the area

* Received Aug. 3, 1955.

** Kobe Marine Observatory. with temperature below $16^{\circ} \mathrm{C}$ and $10^{\circ} \mathrm{C}$ at the depth of $100 \mathrm{~m}$ and $200 \mathrm{~m}$ respectively in lat. $31^{\circ} 40^{\prime} \mathrm{N}$ to $33^{\circ} \mathrm{N}$ and long. $137^{\circ} \mathrm{E}$ to $138^{\circ} 30^{\prime} \mathrm{E}$. Between this cold region and the southern warm region, there was a zone with steep gradient in water temperature distribuiton, where the slope of the isotherms in vertical sections was large. In the cold region the upwelling of the isotherms was conspicuous below the depth of $200 \mathrm{~m}$ and there were less haline waters near the surface. Furthermore, the minimum chlorinity layer was located at shallower depth than in the southern region with haline waters more than $19.20 \%$ at $100 \sim$ $300 \mathrm{~m}$ depth. According to the result of dynamical computations, the main current of the Kuroshio flowed along the zone with steep gradient in water temperature distribution and the westerly current induced by a cyclonic vortex was north of the cold region. Between $N_{2}$ and $N_{3}$, a strong easterly current was found, which seemed to be a branch of the Kuroshio. Current velocity in the main current was more than $30 \mathrm{~cm} / \mathrm{sec}$ at the depth of $600 \mathrm{~m}$ at which minimum chlorinity layer was located, but below this depth the current was weak.

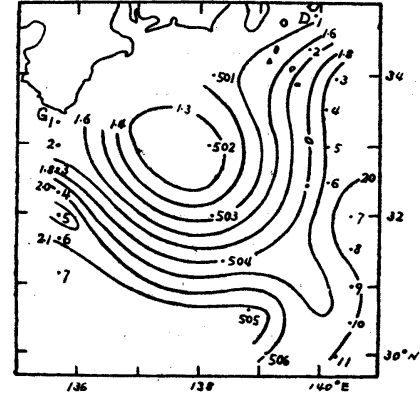

(b) Observation B

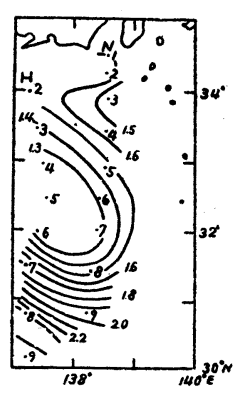

(a) Observation A
Fig. 1. Location of observation stations and geopotential topography of the sea surface referred to the 800 -decibar surface. 


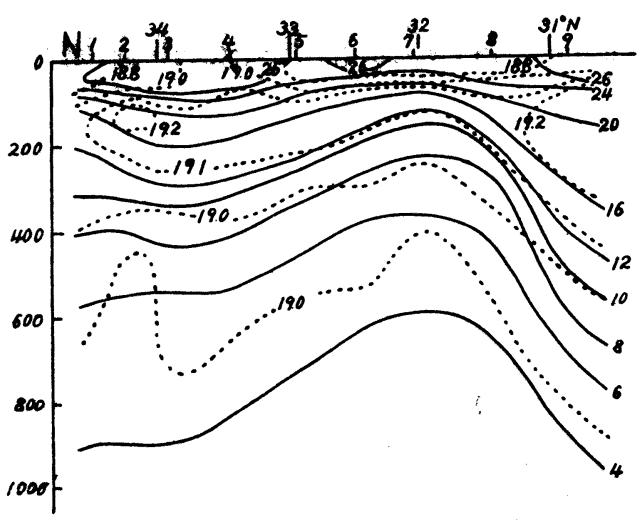

(a) Observation $\mathrm{A}$

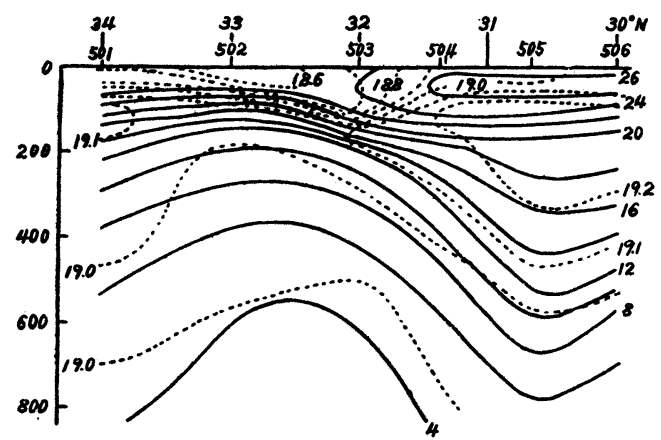

(b) Observation $\mathrm{B}$

Fig. 2. Vertical distributions of water temperature (full line) and chlorinity (broken line).

Since such state was seen as common one, the thickness of the portion with strong current was small in the cold region, while it was large south and north of that region. From the above, it is deduced that the Kuroshio flowed in lat. $31^{\circ} \sim 32^{\circ} \mathrm{N}$ south of Enshu-nada and the value of the current velocity was considerably large.

Observation B

The cold region and the main current of the Kuroshio seems to have been displaced northward compared with the case of observation A judging from water temperature distribution. However, the general situation that the warm region was bsoerved south of the Kuroshio which flowed round the cold region and so on, was similar to that in the observation $A$. The value of chlorinity near the surface in the cold region was about $18.50 \%$ and decreased by about $0.20 \%$. The current velocity decreased in general and was about a half

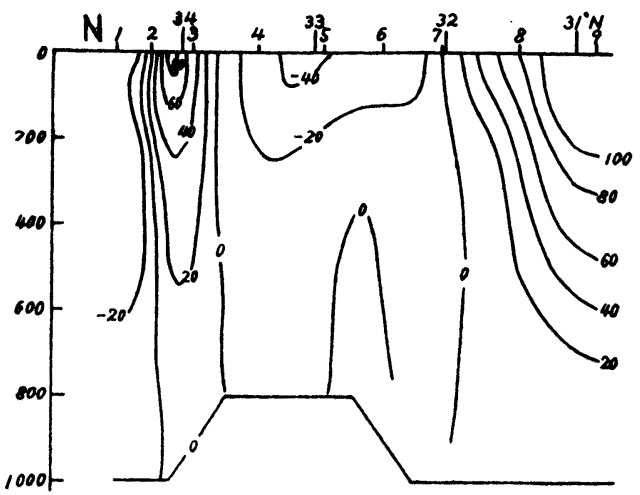

(a) Observation $\mathbf{A}$

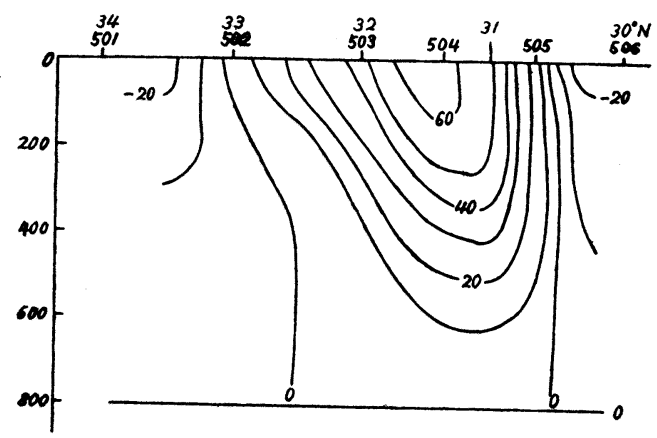

(b) Observation $\mathrm{B}$

Fig. 3. Vertical distributions of current velocity obtained by dynamical computation $(\mathrm{cm} / \mathrm{sec})$. Positive values mean the eastward flow.

of that in observation A. This fact is to be expected from the decreasing in the slope of the isotherms, because the density in this sea area depends mainly upon water temperature. The strength of the cyclonic vortex around the cold region seems to be weaker considering from geopotential topography. Off Shionomisaki, the current axis was located in lat. $32^{\circ} 30^{\prime} \mathrm{N}$ and the Kuroshio flowed southeastward with maximum velocity above $1 \mathrm{~m} / \mathrm{sec}$ which is more than that off Omaesaki, whereas the breadth of the portion with strong current was less.

$\S 3$. As stated above, the cold region and the Kuroshio were displaced northward and the current velocity decreased during about 10 days. Since Sections $N_{1} \sim N_{9}$ and $501 \sim$ 506 were nearly in long. $138^{\circ} 15^{\prime} \mathrm{E}$, it is significant to compare both vertical sections. If we assume that the distance of vertical displacement determined from the distribution of density in situ represents the real 


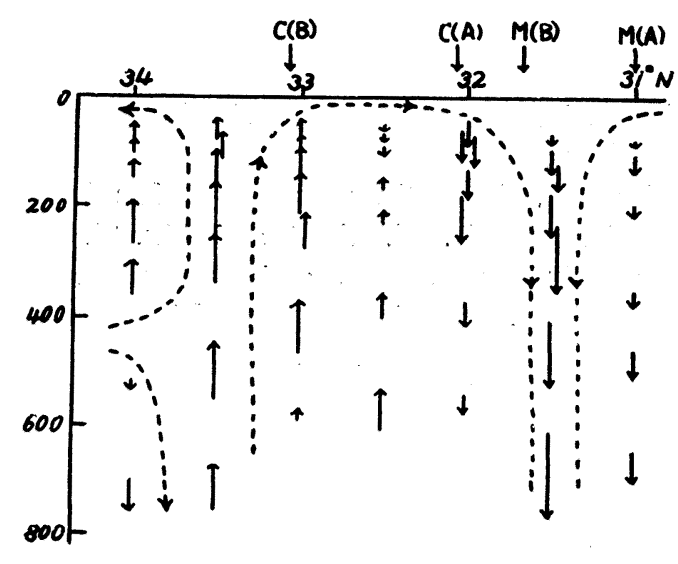

Fig. 4. Distribution of the vertical displacement of the isosteres in the section.

$C(A)$ : center of the cold region in obs. A

$M(A)$ : main current of the Kuroshio in obs. A

value, the mean vertical motion within the period can be obtained. The difference of the depth of the isosteres in the section is shown in Fig. 4, which indicates that ascending and descending motions existed north and south, respectively of the center of the cold region in observation A. Therefore the circulation shown by dotted lines is deduced in the vertical section. The ascending motion was conspicuous near the center of the cold region in the observation $B$, while the descending one was remarkable near the current axis of the Kuroshio in the observation $B$. The maximum value of the distance was about $160 \mathrm{~m}$ in lat. $31.5^{\circ} \mathrm{N}$ and the velocity corresponding to that was $16.8 \times 10^{-5} \mathrm{~cm} / \mathrm{sec}$.

Next, horizontal divergence is computed from equation of continuity by using the above data. Since $\frac{\partial w}{\partial z}$ is to be obtained from the distribution of vertical velocity, horizontal divergence is obtained as $-\frac{\partial w}{\partial z}$. The distribution of horizontal divergence shown in Fig. 5 indicates that above the layer of $100 \mathrm{~m}$ depth convergence was remarkable south of lat. $32.5^{\circ} \mathrm{N}$, and divergence was observed north of it, while on the contrary, below the depth of $100 \mathrm{~m}$ the southern and northern part there were convergent and divergent area, respectively.

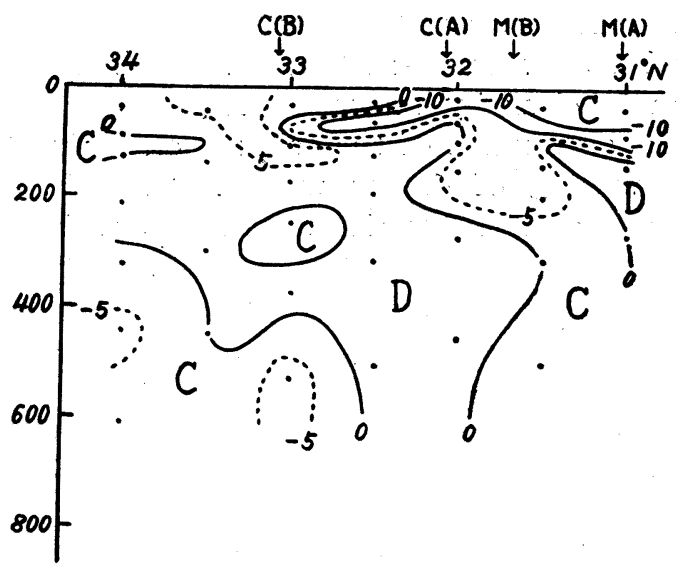

Fig. 5. Distribution of horizontal divergence in the section. (unit: $\times 10^{-7}$ C.G.S.)

But a little conspicuous convergent region was seen below the depth of $400 \mathrm{~m}$ north of lat. $33^{\circ} \mathrm{N}$.

Though the vertical motion in deeper layers can not be known, the relation among the variation of the oceanographical condition, the vertical motion and the horizontal divergence is considered. In a cyclonic vortex around the cold region in observation A, downward motion and convergence near the surface were seen as expected. The descending motion developed south of the center of the cold region and was very weak north of it, although the region was approximately axial-symmetric. However, convergence above the layer of $100 \mathrm{~m}$ depth was also conspicuous north of the center. It was made clear that in observation $B$ chlorinity was low in lat. $32^{\circ} \sim 33^{\circ} \mathrm{N}$ by the influence of converging less haline waters, which were transported downwards and decreased chlorinity at $100 \mathrm{~m}$ depth in lat. $32^{\circ} \mathrm{N}$. Furthermore, steep horizontal gradient between the less haline and more haline waters from south was in the convergent region north of the main current of the Kuroshio in observation A. In general, the values of convergence and divergence were large above the layer of $200 \mathrm{~m}$ depth, but there was a little large convergent region below the depth of $400 \mathrm{~m}$ in the northern portion. In observation $\mathrm{B}$, the center of the cold region was located in lat. $33^{\circ} \mathrm{N}$ where upward motion was predominant, and 
the main current existed in lat. $31^{\circ} 40^{\prime} \mathrm{N}$ where downward motion developed. It was made clear by many oceanographers that the appearance of the cold region is due to upwelling of deeper waters. Though we can not identify the appearance with the displacement, the latter seems also to be closely related to vertical motion. Accordingly, it is deduced that, in the cold region convergent was predominant near the surface by a cyclonic vortex and descending motion developed, but the region was displaced towards the divergent area with descending motion.

$\S 4$. The author has discussed the variation of the oceanographical condition in about 10 days off Enshu-nada and considered the displacement of the cold region. A theoretical consideration will be given in another paper.

Finally, the author expresses his hearty thanks to Mr. Y. Fujii and Mr. T. Ichie for their kind advice and encouragement, and to Mr. Y. Shimomura for his assistance in preparing manuscript.

\section{References}

1) M. Uda: On the recent anomalous hydrographic conditions of the Kuroshio. Rep. Imp. Fish. Inv. St. No. 10, 1940.

2) T. Ichie: On the variation of oceanic circulation (VI). Geophys. Mag. Vol. 25, No. 3 4, 1954. 